\title{
Influenza vaccine match with circulating strains and indicators of influenza strain impact - Canada 1980 to 1992
}

Edward Ellis MD MPH FRCPC, John M Weber PhD SCM(CCM), Wilf Cuff PhD, Susan G Mackenzie PhD

E Ellis, JM Weber, W Cuff, SG Mackenzie. Influenza vaccine match with circulating strains and indicators of influenza strain impact - Canada 1980 to 1992. Can J Infect Dis 1998;9(3):143-148.

OBJECTIVES: To determine the similarity between influenza vaccine antigens and viruses associated with laboratoryconfirmed infections by virus type/subtype, strain and influenza season; to correlate pneumonia and influenza hospitalization and mortality rates with the number of laboratory-confirmed influenza infections in an influenza season; and to develop predictive indicators of the likely incidence of current strains in the following season.

DESIGN: Ecological study using national laboratory, pneumonia and influenza hospitalization and mortality data.

SETTING: Canada, influenza seasons from 1980 to 1992.

POPULATION STUDIED: Individuals with laboratory-confirmed influenza infections, pneumonia and influenza hospitalizations or deaths.

INTERVENTION: Influenza immunization.

MAIN RESULTS: Similarity of circulating strains and vaccine antigens was $99 \%$ for A(H1N1), $65 \%$ for A(H3N2) and $65 \%$ for B strains. During outbreaks, pneumonia and influenza hospitalization, and mortality rates increased $19 \%$ or less and $21 \%$ or less for $\mathrm{A}(\mathrm{H} 1 \mathrm{~N} 1)$, respectively; $28 \%$ or less and $51 \%$ or less for $\mathrm{A}(\mathrm{H} 3 \mathrm{~N} 2)$, and $19 \%$ or less and $16 \%$ or less for B strains. There were usually fewer than 25 laboratory-confirmed $A(H 1 N 1)$ infections with a particular strain in a season if there had been more than 25 infections with similar strains the previous season. For A(H3N2), the figure was 100, and for B it was 150 .

CONCLUSIONS: Matches were excellent for A(H1N1) and good for A(H3N2) plus B strains. Hospitalization and mortality rates increased substantially during outbreaks, eg, estimated 1609 excess deaths during a widespread A(H3N2) outbreak. This study identifies relationships that provide some ability to predict the incidence of a particular influenza strain in a coming season based on the incidence of strains similar to it in the previous season.

Key Words: Influenza incidence, Influenza-related hospitalizations and mortality, Influenza vaccine

\section{Appariement du vaccin antigrippal avec les souches circulantes et indicateurs de l'impact des souches grippales au Canada de 1980 à 1992}

OBJECTIFS : Déterminer la ressemblance entre les antigènes du vaccin antigrippal et les virus associés à des infections confirmées en laboratoire par type/sous-type viral, souche et saison de la grippe ; corréler le taux des hospitalisations dues à la grippe et aux pneumonies et le taux de mortalité avec le nombre d'infections grippales confirmées en laboratoire pendant une saison de la grippe ; et concevoir des indicateurs prédictifs de l'incidence probable des souches actuelles au cours de la saison suivante.

MODÈLE : Étude écologique utilisant les données d'un laboratoire national, des hospitalisations liées aux pneumonies et à la grippe, et

voir page suivante

Health Canada, Laboratory Centre for Disease Control, Ottawa, Ontario

Correspondence and reprints: Dr Edward Ellis, Ottawa-Carleton Health Department, 495 Richmond Road, Ottawa, Ontario K2A 4 A4.

Telephone 613-724-4216, fax 613-724-4152,e-mail ellised@rmoc.on.ca

Received for publication April 23, 1997. Accepted September 23, 1997 
de la mortalité.

CONTEXTE : Saisons de la grippe au Canada de 1980 à 1992.

POPULATION ÉTUDIÉE : Individus avec des infections grippales confirmées en laboratoire, individus hospitalisés à cause d'une pneumonie ou d'une grippe ou décédés. INTERVENTION : Vaccination contre la grippe.

PRINCIPAUX RÉSULTATS : La ressemblance entre les souches circulantes et les antigènes du vaccin était de $99 \%$ pour les souches A (H1N1), de $65 \%$ pour les souches A (H3N2) et de $65 \%$ pour les souches B. Pendant les éclosions, les hospitalisations dues aux pneumonies et à la grippe, et les taux de mortalité ont augmenté respectivement de $19 \%$ ou moins et de $21 \%$ ou moins pour la souche A (H1N1) et A (H3N2); De $28 \%$ ou moins et de $51 \%$ ou moins pour la souche A (H3N2), et de $19 \%$ ou moins et de $16 \%$ ou moins pour la souche B. Généralement, il y avait moins de 25 infections à souche A (H1N1) confirmées en laboratoire avec une souche particulière dans une saison si on avait observé plus de 25 cas d'infections avec des souches analogues la saison précédente. Pour la souche A (H3N2), le chiffre était 100 , et pour la souche B, le chiffre était 150 .

CONCLUSIONS : L'appariement était excellent pour les souches A (H1N1) et bon pour les souches A (H3N2) et B. Les taux d'hospitalisation et de mortalité augmentaient considérablement pendant les éclosions, par exemple, un surplus estimé de 1609 décès pendant une éclosion importante causée par la souche A $(\mathrm{H} 3 \mathrm{~N} 2)$. La présente étude identifie les relations qui permettent de prévoir l'incidence d'une certaine souche spécifique du virus grippal dans la saison à venir en se basant sur l'incidence des souches analogues identifiées au cours de la saison précédente.

$\mathrm{L}$ ate each winter, immunization advisory committees in the northern hemisphere must recommend the antigenic composition of influenza vaccine for the next season $(1,2)$. As much as six months is required for the production, quality control and distribution to allow the vaccine to be ready for the following September. Decisions are based on worldwide surveillance of outbreaks, antigenic analysis of recent influenza isolates, and their transmissibility and ability to move between geographic areas or continents, growth characteristics of the viruses, human antibody response to candidate vaccine antigens, and predictions as to which influenza strains will probably cause outbreaks next season.

Our objectives were to determine the similarity between influenza vaccine antigens and viruses associated with laboratory-confirmed infections by virus type/subtype, strain and influenza season; to correlate pneumonia and influenza hospitalization and mortality rates with the number of laboratory-confirmed infections in an influenza season; and to develop predictive indicators of the likely incidence of current strains in the following season.

\section{MATERIALS AND METHODS}

Surveillance of influenza strains: Participating provincial, hospital and university virus laboratories reported influenza virus isolations and seroconversions weekly by telephone during the study to the Bureau of Communicable Disease Epidemiology at Health Canada's Laboratory Centre for Disease Control, Ottawa, Ontario (LCDC) during the study. In addition, laboratories were encouraged to send selected isolates to LCDC's National Laboratory for Special Pathogens. The selected isolates included up to five of the first isolates of the season, $10 \%$ of subsequent ones slected systematically, those from special outbreaks and unusual late season activity, and any other isolates that could not be easily identified with the ' $\mathrm{i}$ nfluenza kit' reagents that LCDC provided annually to data reporting virus laboratories.

Strains representative of those most commonly isolated during the season and unusual strains that differed from them antigenically were periodically sent to the World Health Organization Collaborating Centre on Influenza at the United States Centers for Disease Control and Prevention, Atlanta, Georgia (CDC) for confirmation of LCDC's findings and identification of isolates that may represent newly emerging variants. Influenza strains by season: To derive, for the purpose of this study, the total number of each influenza virus type/subtype and strain for each influenza season from 1980 through 1992, the following definitions and assumptions were applied to the raw data.

A season was defined as July 1 through June 30 of the subsequent year because this encompasses the prime influenza immunization period of September to November and outbreaks that tend to occur annually from late November through April.

Strains were considered to be similar to the vaccine strain if they were not more than twofold less reactive in hemagglutination-inhibition (HI) tests with fowl or ferret antivaccine strain serum (3). For example, in the $1985 / 86$ season, antiserum to B/USSR/100/83 was eightfold less reactive with $\mathrm{B} / \mathrm{Canada} / 3 / 85$ than with B/USSR. Therefore B/Canada was not considered to be similar to the vaccine strain.

When laboratory confirmation of influenza infection did not produce subtype or strain identification, the strain and subtype distribution of the nonsubtyped viruses were assumed to be the same as that for viruses for which subtype and strain information were available. On average, $27 \%$ of influenza A viruses were identified at least to subtype (median annual percentage was $38 \%$ with a range of $8 \%$ to $53 \%$ ).

In some seasons provincial and hospital laboratories did not have the reagents or resources to identify definitively the strains of influenza viruses actually in circulation. The general strain designations given by these laboratories were revised to be consistent with the more specific strain identifications made at LCDC and $\mathrm{CDC}$.

Impact of previous influenza seasons: To assess the ability of past seasons' influenza strains to induce immunity that persists and protects against antigenically related influenza strains expected to predominate in a current season, the impact of the previous years' infections with the same or related strains was assessed. Data included the number of laboratoryconfirmed infections that occurred during the three previous influenza seasons (eg, 1983/84 to 1985/86) for the same type/subtype multiplied by the ability of antibody produced by the virus strain circulating in the previous seasons to react by 
TABLE 1

Similarity of laboratory-confirmed influenza infections with vaccine antigens, Canada, 13 seasons (1980/81 to 1992/93)

\begin{tabular}{|c|c|c|c|c|c|c|c|}
\hline \multirow{3}{*}{$\begin{array}{l}\text { Season } \\
1980 / 81\end{array}$} & \multicolumn{7}{|c|}{ Influenza type (subtype) } \\
\hline & \multicolumn{2}{|c|}{$\mathrm{A}(\mathrm{H} 1 \mathrm{~N} 1)$} & \multicolumn{2}{|c|}{$\mathrm{A}(\mathrm{H} 3 \mathrm{~N} 2)$} & \multicolumn{2}{|l|}{ B } & \multirow{2}{*}{$\begin{array}{c}\text { All } \\
543 / 676 \\
(80.3 \%)\end{array}$} \\
\hline & Brazil/11/78-like* & $\begin{array}{l}207 / 207^{+} \\
\left(100 \%^{\ddagger}\right)\end{array}$ & Bangkok/1/79-like & $\begin{array}{r}330 / 463 \\
(71.3 \%)\end{array}$ & $\begin{array}{l}\text { Singapore/222/79- } \\
\text { like }\end{array}$ & $\begin{array}{c}6 / 6 \\
(100 \%)\end{array}$ & \\
\hline $1981 / 82$ & Brazil/11/78-like & $\begin{array}{c}2 / 2 \\
(100 \%)\end{array}$ & Bangkok/1/79-like & $\begin{array}{l}16 / 24 \\
(66.7 \%)\end{array}$ & $\begin{array}{l}\text { Singapore/222/79- } \\
\text { like }\end{array}$ & $\begin{array}{l}23 / 163^{\S} \\
(14.1 \%)\end{array}$ & $\begin{array}{l}41 / 189 \\
(21.7 \%)\end{array}$ \\
\hline 1982/83 & Brazil/11/78-like & $\begin{array}{c}4 / 4 \\
(100 \%)\end{array}$ & Bangkok/1/79-like & $\begin{array}{c}839 / 1006 \\
(83.4 \%)\end{array}$ & $\begin{array}{l}\text { Singapore/222/79- } \\
\text { like }\end{array}$ & $\begin{array}{c}130 / 130 \\
(100 \%)\end{array}$ & $\begin{array}{c}973 / 1140 \\
(85.4 \%)\end{array}$ \\
\hline $1984 / 85$ & Chile/1/83-like & $0 / 0(0 \%)$ & Philippines/2/82-like & $\begin{array}{c}715 / 715 \\
(100 \%)\end{array}$ & USSR/100/83-like & $\begin{array}{l}102 / 116 \\
(87.9 \%)\end{array}$ & $\begin{array}{l}817 / 831 \\
(98.3 \%)\end{array}$ \\
\hline $1985 / 86$ & Chile/1/83-like & $\begin{array}{c}0 / 16^{* *} \\
(0 \%)\end{array}$ & Phillipines/2/82-like & $\begin{array}{r}722 / 784 \\
(92.1 \%)\end{array}$ & USSR/100/83-like & $\begin{array}{c}0 / 759^{++} \\
(0 \%)\end{array}$ & $\begin{array}{l}722 / 1559 \\
(46.3 \%)\end{array}$ \\
\hline 1986/87 & $\begin{array}{l}\text { Chile/1/83-like, } \\
\quad \text { Taiwan/1/86-like }{ }^{\ddagger \ddagger}\end{array}$ & $\begin{array}{c}579 / 579 \\
(100 \%)\end{array}$ & Mississippi/1/85-like & $\begin{array}{c}6 / 6 \\
(100 \%)\end{array}$ & Ann Arbor/1/86-like & $\begin{array}{c}0 / 10^{++} \\
(0 \%)\end{array}$ & $\begin{array}{l}585 / 595 \\
(98.3 \%)\end{array}$ \\
\hline 1988/89 & Taiwan/1/86-like & $\begin{array}{c}803 / 803 \\
(100 \%)\end{array}$ & Sichuan/2/87-like & $\begin{array}{c}0 / 64^{\S \S} \\
(0 \%)\end{array}$ & Victoria/2/87-like & $\begin{array}{l}105 / 110 \\
(95.5 \%)\end{array}$ & $\begin{array}{l}908 / 977 \\
(92.9 \%)\end{array}$ \\
\hline $1989 / 90$ & Taiwan/1/86-like & $\begin{array}{c}7 / 7 \\
(100 \%)\end{array}$ & Shanghai/11/87-like & $\begin{array}{c}997 / 1005 \\
(99.2 \%)\end{array}$ & Yamagata/16/88-like & $\begin{array}{c}15 / 68 \\
(22.1 \%)^{\S \S}\end{array}$ & $\begin{array}{c}1019 / 1080 \\
(94.4 \%)\end{array}$ \\
\hline 1990/91 & Taiwan/1/86-like & $0 / 0$ & Shanghai/16/89-like & $\begin{array}{c}0 / 94 * * * \\
(0 \%)\end{array}$ & Yamagata/11/88-like & $\begin{array}{c}897 / 958 \\
(93.6 \%\end{array}$ & $\begin{array}{c}897 / 1052 \\
(85.3 \%)\end{array}$ \\
\hline 1991/92 & Taiwan/1/86-like & $\begin{array}{l}79 / 79 \\
(100 \%)\end{array}$ & Beijing/353/89-like & $\begin{array}{c}327 / 1208^{t+t} \\
(27.1 \%)\end{array}$ & Panama/45/90-like & $\begin{array}{l}60 / 60 \\
(100 \%)\end{array}$ & $\begin{array}{c}466 / 1347 \\
(34.6 \%)\end{array}$ \\
\hline $1992 / 93$ & Texas/36/91-like & $\begin{array}{l}12 / 12 \\
(100 \%)\end{array}$ & Beijing/353/89-like & $\begin{array}{c}77 / 759^{\ddagger \neq \neq} \\
(10.1 \%)\end{array}$ & Panama/45/90-like & $\begin{array}{c}809 / 809 \\
(100 \%)\end{array}$ & $\begin{array}{l}898 / 1580 \\
(56.8 \%)\end{array}$ \\
\hline $\begin{array}{l}\text { All seasons } \\
\text { combined }\end{array}$ & & $\begin{array}{c}2012 / 2041^{+} \\
(98.6 \%)^{\ddagger}\end{array}$ & & $\begin{array}{c}4303 / 6456^{+} \\
\left(64.9 \%^{\ddagger}\right) \\
\end{array}$ & & $\begin{array}{c}2766 / 4261^{+} \\
64.9 \%^{\ddagger} \\
\end{array}$ & $\begin{array}{c}9081 / 12,760^{+} \\
\left(71.2 \%^{\ddagger}\right) \\
\end{array}$ \\
\hline
\end{tabular}

*Vaccine strain; ${ }^{\dagger}$ Derived number of isolates, detections and seroconversions of the vaccine-like and similar strains/All isolates, detections and seroconversions of the type (subtype); ${ }^{*}$ Percentage match; ${ }^{\S}$ Buenos Aires/37/79-like was the predominant B strain; "Bangkok/1/79-like, the predominant A (H3H2) strain, was similar to Philippines/2/82-like strains; ${ }^{* *}$ Taiwan/1/86-like was the predominant A (H1N1) strain; ${ }^{+t}$ Canada/3/85-like (related to Ann Arbor/1/86-like) was probably the only B strain circulating; ${ }^{\neq \neq}$Taiwan/1/86 was issued as a supplemental monovalent vaccine; ${ }^{\$ S}$ Victoria/2/87-like was the predominant B strain; "Shanghai/11/87-like was the predominant A (H3H2) strain; ${ }^{* * * B e i j i n g / 353 / 89-l i k e ~ w a s ~ t h e ~ p r e d o m i n a n t ~ A(H 3 N 2) ~ s t r a i n ; ~}{ }^{++1}$ Four distinguishable $\mathrm{A}(\mathrm{H} 3 \mathrm{~N} 2)$ strains predominated; ${ }^{* \neq \pm}$ Beijing/32/92-like was the predominant $\mathrm{A}(\mathrm{H} 3 \mathrm{~N} 2)$ strain

HI with the strain expected in the current season. Thus, for example, the value assigned to one laboratory-confirmed infection in the previous years by a strain that was serologically identical to the strain of interest in the current season was 1 . This value was derived by $\mathrm{X} / \mathrm{Y}$ where $\mathrm{X}=\mathrm{HI}$ antibody titre to the strain of interest when reacted with antiserum raised against a previously infecting strain, and $\mathrm{Y}=\mathrm{HI}$ antibody titre to the previously infecting strain when reacted with antiserum raised to itself. When X was fourfold less than Y, the impact of previous infections would be considered to be reduced by one quarter.

Hospitalization and mortality: National pneumonia and influenza hospitalization data (International Classification of Diseases [ICD]-9 codes 480 to 483 and 485 to 487 ; defined by Statistics Canada as hospital discharges, transfers out or deaths in hospital) were only available by fiscal year for the period April 1980 to March 1992 (4-14). Mortality data (ICD-9 codes 480 to 487 ) by month for the period from July 1980 to June 1993 were obtained from custom tabulations prepared by Statistics Canada. Dates of onset for laboratory-confirmed influenza cases (15-24), and Manitoba hospitalization and mor- tality data (personal communication) were used to define each specific four- to eight-month national influenza season to calculate deaths/100,000 population/month during the influenza season.

Analyses were restricted to persons aged 65 years and older for two reasons. First, they experience the highest agespecific rates of influenza-related hospitalization and mortality (25-27). Second, $90 \%$ of pneumonia and influenza deaths during the period under study were in this age group. Influenza (only) hospitalization and mortality rates were not used because they are unstable and underestimate the impact of influenza (28).

\section{RESULTS}

Comparison of circulating influenza viruses with vaccine antigens: There were 12,760 laboratory-confirmed influenza infections (virus isolates, detections and seroconversions) reported to LCDC during 13 influenza seasons from July 1980 through June 1993 (Figure 1, Table 1). Strain identifications for $71 \%$ (9081) were similar to the vaccine antigens for the respective season. Season-specific values ranged from $22 \%$ to 


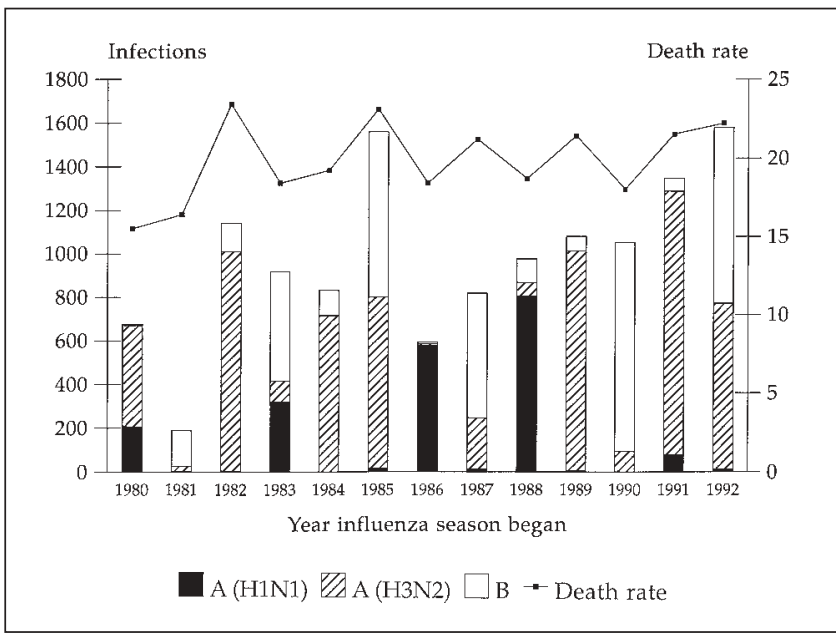

Figure 1) Laboratory-confirmed influenza infections and relations to pneumonia and influenza death rate, Canada, 1980 to 1992. Pneumonia and influenza deaths (International Classification of Diseases 9 480 to 487) per 100,000 population aged 65 years and older per month during the influenza season across Canada (four to eight months depending on the season)

$98 \%$ with a median of $81 \%$ and a mean of $72 \%$. For all seasons combined, $99 \%$ of $\mathrm{A}(\mathrm{H} 1 \mathrm{~N} 1), 65 \%$ of $\mathrm{A}(\mathrm{H} 3 \mathrm{~N} 2)$ and $65 \%$ of $\mathrm{B}$ strain identifications were similar to the vaccine antigens. The three means did not change appreciably when analysis was limited to seasons with at least 100 laboratory-confirmed infections for a particular type/subtype.

There were four mismatches when large numbers of laboratory-confirmed infections were not similar to the vaccine antigens: $\mathrm{A}(\mathrm{H} 3 \mathrm{~N} 2)$ in 1991/92 when the expected Beijing/353/89-like and three related but, by the criteria, dissimilar or distinguishable viruses all predominated; $\mathrm{A}(\mathrm{H} 3 \mathrm{~N} 2)$ in 1992/93 when the Beijing/32/92-like strain predominated rather than the expected Beijing/353/89-like strain; B in $1985 / 86$ when Canada/3/85-like virus was probably the only B strain circulating rather than the expected USSR/100/83like virus, which had been gradually increasing in circulation; and $B$ in 1987/88 when the new Victoria/2/87-like virus was more abundant than the expected Ann Arbor/1/86-like virus. Other mismatches occurred in seasons when only relatively small numbers of laboratory-confirmed infections were involved: influenza A(H1N1) in 1985/86; A(H3N2) in 1988/89 and 1990/91; and B in 1981/82, 1986/87 and 1989/90 (Table 1).

Pneumonia and influenza hospitalizations, and deaths during years with increased influenza activity: Pneumonia and influenza hospitalization, and mortality rates were positively correlated to the number of laboratory-confirmed infections in the season $(r=0.82,0.78$ with $\mathrm{P}<0.01)$ (Figure 2$)$. The lowest rate of pneumonia and influenza hospitalizations (912/100,000 population aged 65 years and older) was in the $1981 / 82$ season when there were relatively few (189) laboratory-confirmed infections. Rates increased by up to $19 \%$ during $\mathrm{A}(\mathrm{H} 1 \mathrm{~N} 1)$ and B outbreaks (eg, 1988/89 and 1990/91, respectively), while $\mathrm{A}(\mathrm{H} 3 \mathrm{~N} 2)$ outbreaks increased rates by up to $28 \%$ (eg, 1982/83).

For mortality due to pneumonia and influenza, the lowest

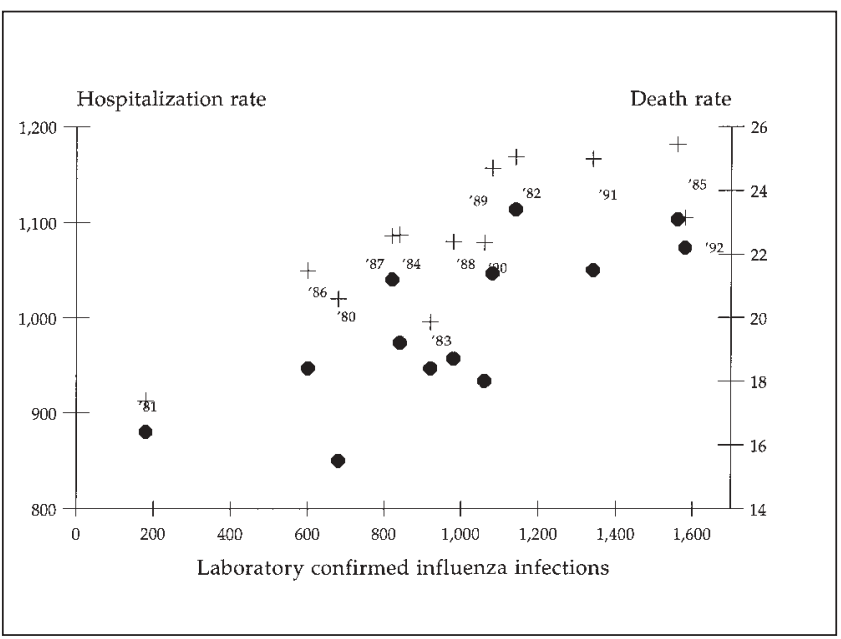

Figure 2) Relationship of pneumonia and influenza hospitalizations and deaths to laboratory-confirmed influenza infections in Canada for influenza seasons from 1980 to 1992. + Hospitalization rates; Death rates

observed rate was 15.5 deaths/100,000 population aged 65 years and older per month during the 1980/81 season. This rate increased by up to $21 \%$ during $\mathrm{A}(\mathrm{H} 1 \mathrm{~N} 1)$ outbreaks (eg, 1988/89), 51\% during A(H3N2) outbreaks, (eg, 1982/83) and $16 \%$ during B outbreaks (eg, 1990/91). The relationship of mortality rates to the derived type/subtype distribution of laboratory-confirmed infections is shown in Figure 1.

Likely incidence of current strains in the following season: The population's experience with similar infections the previous season usually had a clear impact on incidence (Figure 3). For A(H1N1), there were usually fewer than 25 laboratoryconfirmed infections with a particular strain in a season if there had been more than 25 infections with similar strains the previous season. For $\mathrm{A}(\mathrm{H} 3 \mathrm{~N} 2)$, there were usually fewer than 100 infections in a season if there were more than 100 infections due to similar strains in the previous season. The one exception was A/Philippines/2/82-like virus, which was active during two seasons including the spring of 1985 and winter of 1985/86 s(17). For B, there were fewer than 150 infections in a season if there were more than 150 infections due to similar strains in the previous season.

This protective effect was seen for similar strains active the previous season only. Experience with similar strains two and three years before the current season had no impact on incidence (data not shown). Likewise, the previous season's influenza vaccine distribution rate had no impact despite an increase during the study period to 107 doses/1000 population in 1990/91 (29) (data not shown).

\section{DISCUSSION}

Data used in this study included a number of limitations and assumptions. First, we assumed that the number of laboratory-confirmed infections paralleled the number of diagnostic tests, and, therefore, the incidence of influenza severe enough to warrant medical attention. Second, the percentage of influenza A infections that were subtyped generally 
decreased in the last half of the study period, possibly due to increased use of direct antigen testing for rapid diagnosis. If those subtyped were not representative of all influenza A infections, there is less certainty in our results for $\mathrm{A}(\mathrm{H} 3 \mathrm{~N} 2)$ in 1991/92 and 1992/93. Third, because strain-specific hospitalization and case fatality rates are not generally available, we also assumed that all strains had equal virulence. This could underestimate the protective value of a past influenza season that caused mild infections not leading to medical care and a laboratory test for influenza, but nevertheless protecting the population against similar viruses the next season. Fourth, circulating strains were designated as similar or dissimilar to vaccine strains based on strain cross-reactivities in HI tests using homologous and heterologous sera raised in chickens or ferrets. This assumes that human results will be the same, which is not necessarily so because most humans are not as immunologically naive. For example, Sugaya et al (30) reported that A/Beijing/352/89 (H3N2) vaccine was $67.5 \%$ effective in children with asthma, even though the epidemic $\mathrm{A} / \mathrm{Ki}-$ takyushu/159/93 virus showed marked antigenic drift from the vaccine strain. Fifth, hospital morbidity data were available nationally only on an April to March fiscal year basis. Each fiscal year contained the end of one influenza season and the beginning of the next. Even if hospitalization data could be grouped by influenza season, they are biased indicators of period incidence. Undercounting can occur when pneumonia or influenza is considered a less serious diagnosis and is overridden by a more serious one. Overcounting can occur if an individual has multiple hospitalizations for the same diagnosis within the year. Sixth, although pneumonia and influenza mortality data are available for specific influenza seasons, we do not know the proportion of the total truly due to influenza for any particular season. It likely varies depending on the virulence of influenza viruses and other circulating respiratory pathogens, such as parainfluenza virus.

Notwithstanding the above limitations, we conclude that the match between circulating influenza viruses and vaccine antigens from 1980/81 through 1992/93 was excellent for $\mathrm{A}(\mathrm{H} 1 \mathrm{~N} 1)$, and good for $\mathrm{A}(\mathrm{H} 3 \mathrm{~N} 2)$ and B. The difficulty in always choosing the correct viral strain for inclusion in vaccine is illustrated by the experience in 1985/86 when Canada/3/85-like virus was essentially the only B strain circulating rather than the expected USSR/100/83-like virus that had been gradually increasing in circulation. In fact, there were four B strains circulating at low levels in 1984/85 with no compelling reason to predict that the strain of $B / C a n a d a / 3 / 85$ isolated in Manitoba early in 1985 would be the influenza B virus that predominated in the $1985 / 86$ season (Table 1). By 1986/87, the antigenically related B/Ann Arbor/1/86-like strain was part of the vaccine.

Our finding that hospitalization rates for pneumonia and influenza increased during outbreaks may be an underestimate or overestimate because the fiscal year of hospitalization data averages parts of two consecutive seasons. The mortality rate increases during outbreaks are probably more reliable. If we apply the baseline rate of 15.5 pneumonia and influenza deaths $/ 100,000$ population aged 65 years and older per month
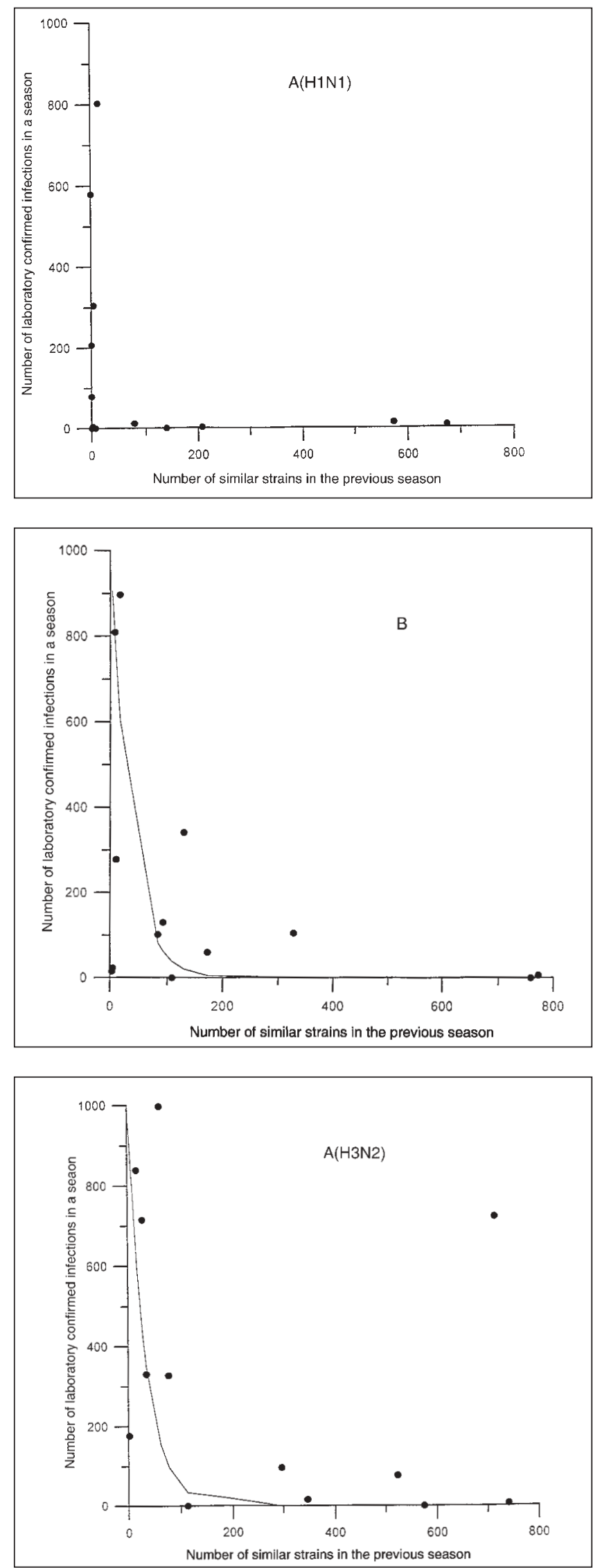

Figure 3) Relationship of laboratory-confirmed influenza infections to previous season's experience, Canada 1980 to 1992 
during influenza season to the 1993 population (31), we would have expected 3154 deaths during a typical six-month influenza season. With a widespread A(H3N2) outbreak, the number of deaths could increase by 1609 deaths. The increase would be 662 for widespread A(H1N1) and 505 for widespread B outbreaks.

The protective effect of infections in previous seasons against similar strains in current seasons has been previously reported (32). This study identifies relationships that provide some ability to predict the incidence of a particular influenza strain in an upcoming season based on the incidence of strains similar to it in the previous season.

ACKNOWLEDGEMENTS: We thank directors and staff of national, provincial, hospital and university virus laboratories who provided first-line influenza surveillance data and viral isolates to the LCDC annually, the staff of the Bureau of Communicable Disease Epidemiology, LCDC, and Statistics Canada.

\section{REFERENCES}

1. National Advisory Committee on Immunization (NACI). Statement on influenza vaccination for the 1996-97 season. Can Commun Dis Rep 1996;22:89-97.

2. Canadian Consensus Conference on Influenza. Can Commun Dis Rep 1993;19:136-42,145-6.

3. Kendal AP, Pereira MS, Shehel J. Concepts and procedures for laboratory based influenza surveillance. Atlanta: United States Department of Health and Human Services, 1982.

4. Statistics Canada. Hospital Morbidity, 1978/79 [cat no 82-206]. Ottawa: Ministry of Supply and Services, 1982.

5. Statistics Canada. Hospital Morbidity, $1979-80$ and $80-81$ [cat no 82-206]. Ottawa: Ministry of Supply and Services, 1984:72-3, 126-7.

6. Statistics Canada. Hospital Morbidity, 1981-82 and 82-83 [cat no 82-206]. Ottawa: Ministry of Supply and Services, 1986: 62-3, 116-7.

7. Statistics Canada. Hospital Morbidity, 1983-84 and 84-85 [cat no 82-206]. Ottawa: Ministry of Supply and Services, 1989:56-7,110-1.

8. Statistics Canada. Hospital Morbidity, 1985-86 [cat no 82-003S]. Health Reports 1989;1(2):Table 2.

9. Statistics Canada. Hospital Morbidity, 1986-87 [cat no 82-003S]. Health Reports 1990;2(2 Suppl 1):30-1.

10. Statistics Canada. Hospital Morbidity, 1987-88 [cat no 82-003S]. Health Reports 1990;2(2 Suppl 2):30-1.

11. Statistics Canada. Hospital Morbidity, 1988-89 [cat no 82-003S]. Health Reports 1991;3(1 Suppl 1):30-1.
12. Statistics Canada. Hospital Morbidity, 1989-90 [cat no 82-003S]. Health Reports 1992;4(1 Suppl 1):30-1.

13. Statistics Canada. Hospital Morbidity, 1990-91 [cat no 82-216] Ottawa: Minister of Industry, Science and Technology, Canada, 1993;30-1.

14. Statistics Canada. Hospital Morbidity, 1991-92 [cat no 82-216]. Ottawa: Minister of Industry, Science and Technology, Canada, 1994;30-1.

15. Laboratory Centre for Disease Control. Influenza - worldwide, Canada, United States. Can Dis Wkly Rep 1984;10:11-2.

16. Laboratory Centre for Disease Control. Influenza surveillance in Canada, 1984-85. Can Dis Wkly Rep1985;11:109-12.

17. Laboratory Centre for Disease Control. Influenza strains in Canada and availability of typing agents. Can Dis Wkly Rep 1986;12:61-2.

18. Laboratory Centre for Disease Control. A summary of influenza activity in Canada, 1985-86 season. Can Dis Wkly Rep 1986;12:133-6.

19. Laboratory Centre for Disease Control. A summary of influenza activity in Canada, 1986-1987 season. Can Dis Wkly Rep $1988 ; 14: 22$

20. Laboratory Centre for Disease Control. A summary of influenza activity in Canada, 1987-1988 season. Can Dis Wkly Rep 1988;14:169-74

21. Laboratory Centre for Disease Control. Influenza activity in Canada, 1988-1989. Can Dis Wkly Rep 1989;15:171-6.

22. Laboratory Centre for Disease Control. Influenza in Canada, 1989-1990 season. Can Dis Wkly Rep 1990;16:185-9.

23. Laboratory Centre for Disease Control. Influenza in Canada, 1990-91 and 1991-92 season season. Can Commun Dis Rep $1992 ; 18: 137-41$

24. Laboratory Centre for Disease Control. Influenza in Canada, 1992-1993 season. Can Commun Dis Rep 1993;19:152-7.

25. Barker WH, Mullooly JP. Impact of epidemic type A influenza in a defined adult population. Am J Epidemiol 1980;112:798-813.

26. Barker WH, Mullooly IP. Pneumonia and influenza deaths during epidemics. Arch Intern Med 1982;142:85-9.

27. Glezen WP, Decker M, Perrotta DM. Survey of underlying conditions of persons hospitalized with acute respiratory disease during influenza epidemics in Houston, 1978-1981. Am Rev Respir Dis 1987;136:550-5.

28. Monto AS. Influenza: Quantifying morbidity and mortality. Am J Med 1987;82(Suppl 6A):20-5.

29. Mackenzie SG. Distribution of influenza vaccine in Canada. Can Dis Wkly Rep 1991;17:128-30.

30. Sugaya N, Nerome K, Ishida M, Matsumoto M, Mitamura K, Nirasawa M. Efficacy of inactivated vaccine in preventing antigenically drifted influenza type A and well-matched type B. JAMA 1994;272:1122-6.

31. Statistics Canada. Postcensal annual estimates of population by marital status, age, sex and components of growth for Canada, provinces and territories, June 1, 1993 and preceding years, cat no 91-210 Annual. Ottawa: Ministry of Industry, Science and Technology, 1993.

32. Foy HM, Allan I, Blumhagen JM, Cooney MK, Hall C, Fox JP. A/USSR and B/Hong Kong vaccine. JAMA 1981;245:1736-40. 


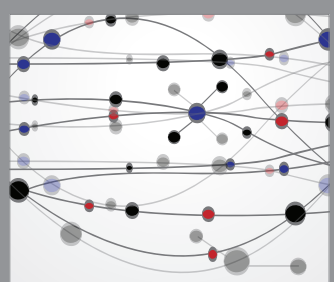

The Scientific World Journal
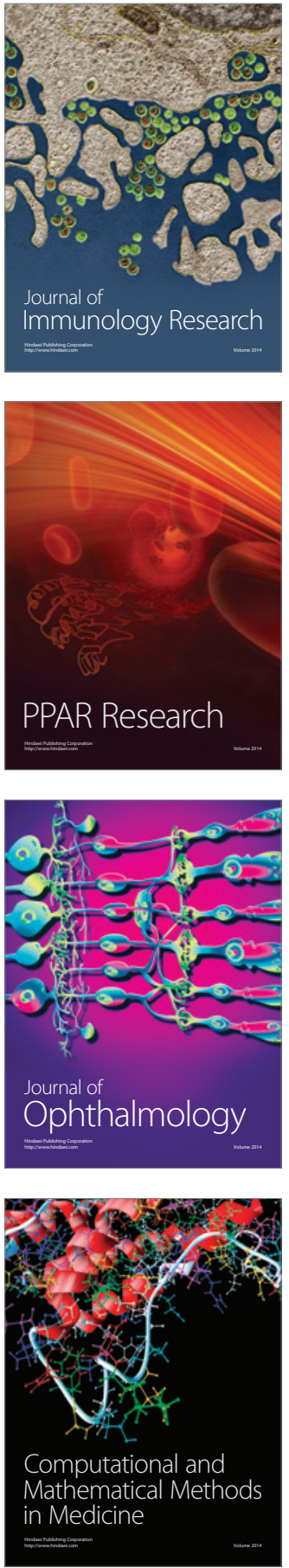

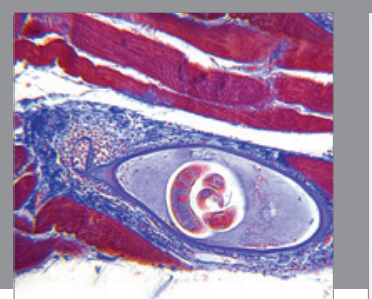

Gastroenterology Research and Practice

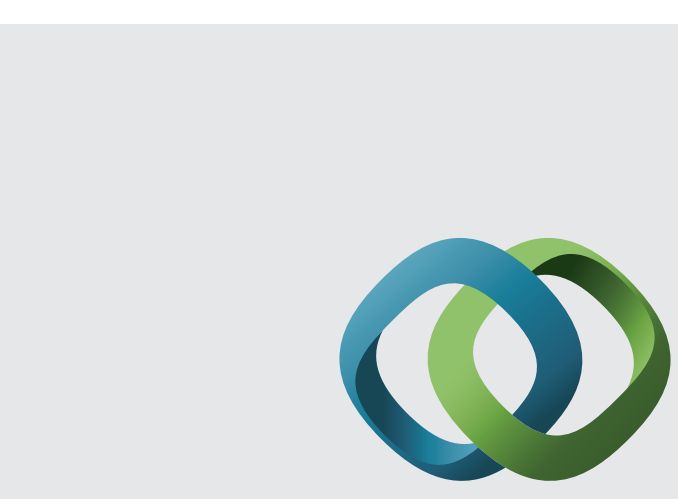

\section{Hindawi}

Submit your manuscripts at

http://www.hindawi.com
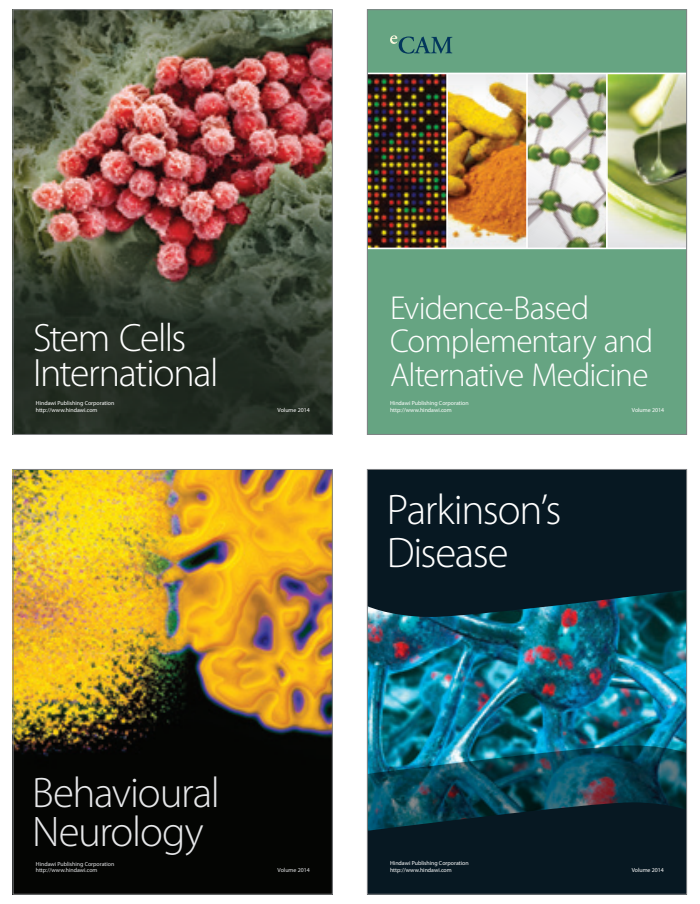
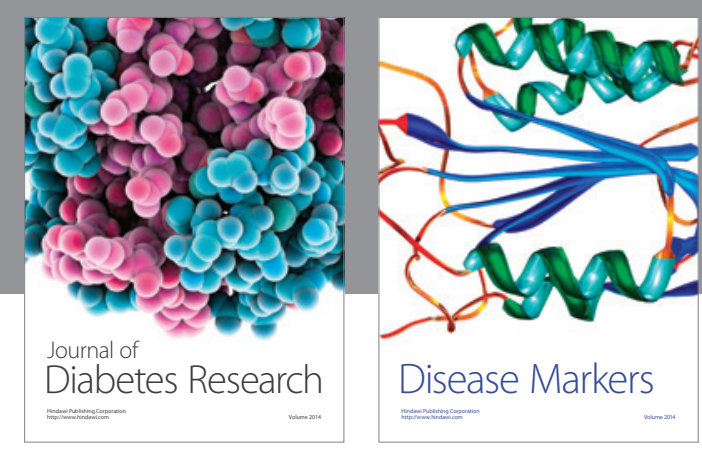

Disease Markers
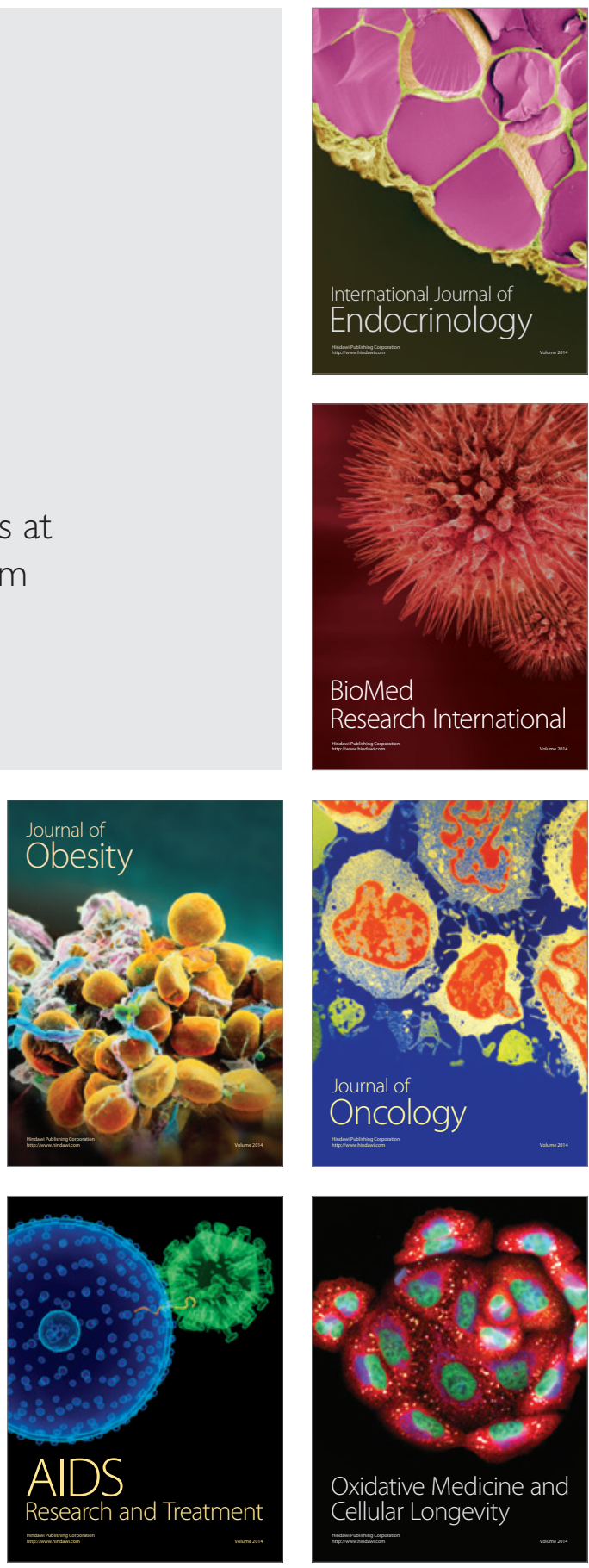